\title{
Effects of different architectural solutions on the thermal behaviour in an unconditioned rural building. The case of an Italian winery
}

\author{
Daniele Torreggiani, Alberto Barbaresi, Francesca Dallacasa, Patrizia Tassinari \\ Department of Agricultural Sciences, University of Bologna, Italy
}

\begin{abstract}
Referring to the wine sector, in the Mediterranean area, most of the wine farms make use of unconditioned above-ground buildings constructed without a specific attention to temperature control, where indoor temperatures easily show trends in disagreement with correct wine-ageing and conservation. Moreover the suitable temperature ranges can differ from wine to wine, and are considerably different from ideal temperatures for human comfort. This study aimed at testing the effectiveness of different architectural elements in improving the thermal behaviour of unconditioned farm buildings, by means of energy simulations validated on an Italian case-study, comparing the data provided by the simulations with different temperature ranges. Results showed the building thermal performance depends on the chosen intervals, some solution played negative or positive role according to the analysed range and in general roof and wall interventions were more effective than orientation and solar shading, and the combination of more strategies allow to achieve improved results.
\end{abstract}

\section{Introduction}

Several food processes requires the product shall be kept within specific temperature intervals in order to achieve good quality. Usually, in the process phases, the food temperature is controlled directly by the equipment (such as fermenters for wine-making,

Correspondence: Alberto Barbaresi, Department of Agricultural Sciences, University of Bologna, viale G. Fanin 48, 40127 Bologna, Italy.

Tel.: +39.051.209.6197

E-mail: alberto.barbaresi@unibo.it

Key words: Thermal performance; unconditioned building; building design; energy simulation; winery.

See online Appendix for additional Tables and Figures.

Received for publication: 1 September 2017.

Accepted for publication: 1 December 2017.

CCopyright D. Torreggiani et al., 2018

Licensee PAGEPress, Italy

Journal of Agricultural Engineering 2018; XLIX:779

doi:10.4081/jae.2018.779

This article is distributed under the terms of the Creative Commons Attribution Noncommercial License (by-nc 4.0) which permits any noncommercial use, distribution, and reproduction in any medium, provided the original author(s) and source are credited. polyvalent tanks for cheese production, etc.). In some food transformations, the final product should be preserved or aged for long periods (even years) before the commercialisation, overall in high quality productions. In these cases the product is located in rooms able to guarantee a proper temperature trend throughout the whole keeping period. To provide suitable environmental conditions, rooms are often air-conditioned.

This solution is mandatory when temperature can affect the food safety, for example in some cheese preservation or ageing. On the contrary, in the wine industry, temperature can influence the product quality but hardly affects its safety.

Therefore buildings hosting the ageing or keeping phases, can be unconditioned. In these situations the wine temperature is in equilibrium with the temperature of the ageing/keeping room. The scientific literature identifies the ranges of ideal temperatures for wines, showing different values depending on several factors, such as type of wine, kind of grapes, area of productions and many more (Marescalchi, 1965; Vogt, 1971).

Interesting data on this topic come from Cooke and Berg (1984) who surveyed Californian cellars, showing the high variety of practices. The conservation temperature of white wines ranged between $7^{\circ} \mathrm{C}$ and $24^{\circ} \mathrm{C}$, with an average temperature of $13^{\circ} \mathrm{C}$ according to the survey of 1971, in 1984 the range changed from $7^{\circ} \mathrm{C}$ to $21^{\circ} \mathrm{C}$ and the recorded average temperature was $13^{\circ} \mathrm{C}$. For red wines the conservation temperature range was found between $10^{\circ} \mathrm{C}$ and $24^{\circ} \mathrm{C}$ (average temperature of $18^{\circ} \mathrm{C}$ ) in 1971 , while in 1984 the range was $7{ }^{\circ} \mathrm{C}-21^{\circ} \mathrm{C}$ (average temperature of $15^{\circ} \mathrm{C}$ ).

Despite the differences in literature, suitable temperatures are mostly close to $15^{\circ} \mathrm{C}$ and a particular attention should be paid to limit the temperature swings as well (Vogt, 1971). Variation of temperatures can rise the risks of pressure changes and cork movements in bottle conservation and can ease the wine overflow in case of small fermentor headspace (Boulton et al., 1998). Moreover, the literature reports the temperatures over $20^{\circ} \mathrm{C}$ can lower the quality more and faster than low temperatures (i.e. $10^{\circ} \mathrm{C}$ ) (Marescalchi, 1965). In wine ageing and conservation, as for all chemical reactions, temperature plays a significant role. Since several chemical reactions with different rate of development are involved, low temperatures help to maintain a balance between the reaction products; on the contrary high temperatures (over $20^{\circ} \mathrm{C}$ ) can spoil or overage some wine (Boulton et al., 1998). On the other side, short periods of low temperatures may have a positive effect since ease the removal of potassium bitartrate, but in general they slow the wine development (even blocking it) and prolong the time of ageing, with remarkable consequences on the winery as well (i.e., more space for storage and more containers are needed; wine cannot be sold for longer periods, and more). The temperature is an overall problem in warm climate - like in Mediterranean region - where summer temperatures are frequently over $20^{\circ} \mathrm{C}$, even indoor. In this area, the majority buildings for keeping and ageing wine, were built in the last century without specific attention to their thermal performance in spite of a proper centennial architectural tradition. 
The wineries inclined to improve the quality of their productions, have often resorted to the installation of a conditioning system neglecting the building thermal insulation. Due to the energy cost rise, the operating costs can prove this solution economically unsustainable. New keeping/ageing room projects, both for new constructions and retrofit interventions, can be designed considering the new technologies for thermal comfort developed in the last decades. In fact, driven by the necessity to reduce energy demand for conditioning, in the recent years, the building industry has offered several solutions to improve building thermal performance. These solutions can involve the systems, such as high-efficiency HVAC, and the building architectural design, such as building envelope insulation, sun shading, window air filtration reduction, building orientation optimisation, and more. As well known, to improve the thermal environment of a keeping/ageing room, the most preforming solution is a combination of both interventions: for example building insulation and efficient conditioning system installation. However the operating costs can be still overall unsustainable for small-medium wine-growing and producing farms. For this reason some farms choose not to install conditioning systems and thus renovates the storage building (or builds a new one) using envelope solutions optimised for conditioned buildings.

The importance of architectural and envelope thermal characteristics in conditioned buildings have been tested and demonstrated in several studies (Baglivo et al., 2014; Rossi and Rocco, 2014), but just a few works analysed their impact on thermal behaviour in free running buildings. Moreover they focus on human thermal comfort (Jiao et al., 2017) or investigate natural temperature distribution (Martin and Canas, 2006). This work aims to investigate the impact of the architectural solutions (insulation, sun shading elements, glazed windows and orientation) on the temperature trend in an unconditioned room. Precisely, the main goal of this work is to assess the effectiveness of different architectural solutions, applied to an unconditioned building, in terms of thermal performances. Moreover it aims to determine if the solutions optimised for conditioned buildings provide positive effects on thermal behaviour of unconditioned building as well. The effectiveness is evaluated by means of three indicators obtained comparing the building temperatures - provided by energy simulations - with temperature ranges specific for wine and human comfort. The simulations are based on a case-study building simulation calibrated and validated on experimental data. The result of the present research can be a method to assess the effect of architectural solutions on human and wine thermal comfort and can provide useful information to drive a sustainable building winery design.

\section{Materials and methods}

The work has been organised as follows: i) a representative building - modelled, calibrated and validated on the basis of experimental data - was identified; ii) a set of architectural design elements (5) and their variations (20) have been defined and modelled; iii) different weather files ( 2 years) have been chosen to run the simulations; iv) the architectural element variations were combined and modelled in all the possible configurations (576) and the related simulations (1152) have been run; v) different thermal comfort intervals (3-2 for wine and 1 for human) have been defined; vi) indicators (3) have been created comparing the simulation results with the thermal comfort.

\section{Case study}

Previous studies (De Rosis et al., 2014; Tinti et al., 2014; Barbaresi et al., 2015a; Verdecchia et al., 2016) allowed to use the energy model of an Italian winery as base model for the present work. The model was calibrated and validated on experimental data on an existing winery (Barbaresi et al., 2017).

The building belongs to Azienda Agricola Branchini farm (Figure 1A) and is used as wine-making and storage room (Figure 1B). It is an above-ground rectangular construction, with the main axis $32^{\circ} \mathrm{NE}$ oriented, it is $27.75 \mathrm{~m}$ long and $18.50 \mathrm{~m}$ wide. The height is variable, between $5.30 \mathrm{~m}$ and $7.00 \mathrm{~m}$. Six equidistant pillars are located along the main axis and virtually divide the internal space in two zones: the north-east zone hosts the area of wine-making phase, the south-west zone is used as storage for bottled wine. The building envelope is made with traditional materials with low thermal performance. The exteriors walls are made with $32 \mathrm{~cm}$ thick plastered concrete brick panels; the floor is a $30 \mathrm{~cm}$ thick concrete slab while the roof is made with a non-insulated slab poured directly on the ground. Five single glazed windows are located on the north-east wall, two metallic doors are located on both the two short sides and a canopy on north-west side protects the grape deliver space. The indoor space is naturally ventilated and has no air-conditioning or ventilation system.

The wine kept in the storage area is preserved in bottles (unconditioned containers), differently, the wine in the wine-making area is stored in fermenters (conditioned containers), entailing the wine in the storage area is more sensitive to the room temperature variations. For this reason the result analysis is applied solely to the storage area. The farm has 20 hectares of vineyards, the aver-

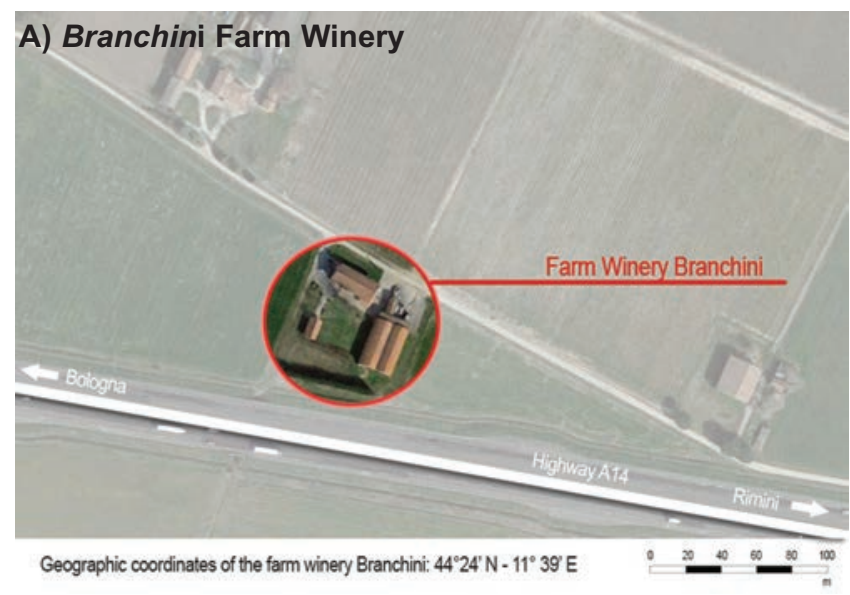

B) Case-study building

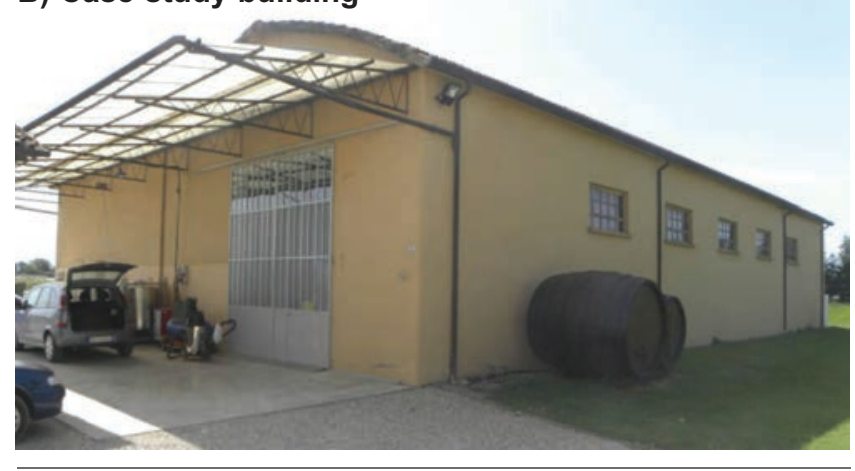

Figure 1. Case study. 
age year production is about 250,000 litres of wine (Sangiovese, Albana, Pignoletto, Chardonnay, Merlot) and a small part (10,000 bottles) is dedicated to classic method sparkling wines.

\section{Design elements and variations}

In this work each tested building is a combination of the different architectural elements. The present work aims to quantify the impact of different architectural element configurations on the building thermal behaviour and, consequently, on the indoor comfort. The first step was the identification of the elements to investigate leading to the following: wall construction, roof construction, orientation, windows and shading surface. The second step has been the definition of their parameters to insert in the simulations. These arguments are widely explained in the following Sections.

\section{External walls (code: $w X X)$}

In this work 6 different external wall constructions have been investigated. Constructions were chosen on the basis of the following criteria: i) construction materials are easy to found for a winemaking farm (or in the construction market or by self-production); ii) constructions are representative of market solutions in terms of different thermal performance combinations (thermal transmittance, time shift, surface mass).

A code (from w01 to w06) is assigned to the 6 investigated constructions: i) $w 01: 12 \mathrm{~cm}$ thick masonry, typical wall construction widespread in Italian traditional countryside. It is characterised by very high transmittance and very low time shift; ii) w02: $26 \mathrm{~cm}$ light weighted concrete blocks, typical wall construction widespread in Italian countryside in the last decades of the previous century. It is characterised by high transmittance and low time shift. The case-study external walls are built with this construction; iii) $w 03: 22 \mathrm{~cm}$ thick wood cross laminated timber (CLT) panels, transmittance and time shift meet Italian law requirements about retrofit intervention in heated rooms; iv) $w 04$ : brick plus $11 \mathrm{~cm}$ thick insulating material: low transmittance and low time shift; v) w05: concrete walls: high transmittance and high time shift; vi) w06: high performance construction, light weighted concrete blocks plus a $50 \mathrm{~cm}$ thick straw-bale layer;

In particular the envelope elements characterised by the codes \#01 and \#02 (both for walls and roof) do not meet law requirements and are representative of the aboveground wineries in the study area (Torreggiani et al., 2011).

In the Appendix (Appendix Table A1), the layers of the 6 constructions are listed and their main thermal values are shown as inserted in the simulation program (the material are listed starting from the external layer). The values listed in Appendix Table A1 (thickness, thermal conductivity, density and specific heat) refer to the single material layer, and all the layers contribute to identify the thermal characteristics of the architectural element (wall or roof) that determine its thermal behaviour. These characteristics are as follows: i) steady-state thermal transmittance $U$ : the rate of heat transferred through a reference surface in a material from one side to the other side $\left[\mathrm{Wm}^{-2} \mathrm{~K}^{-1}\right]$. For new constructions in this zone $U<0.34 \mathrm{Wm}^{-2} \mathrm{~K}^{-1}$ according to the law (Italian Regulation, 1993 ); ii) decrement factor $F_{a}$ : the ratio of the modulus of the periodic thermal transmittance $Y_{m n}$ (in the $24 \mathrm{~h}$ ) to the steady-state thermal transmittance. It can be seen as an index of attenuation of the thermal flux through the wall. It is related to the time shift (Ente Italiano di Normazione, 2008). $F_{a}<0.15$ is considered excellent for the Italian law (Italian Regulation, 1993); iii) time shift $\Phi$ : it is the temporal difference between the time in which the maximum temperature is recorded on the external surface of the architectural element and the time in surface which is recorded in the internal $[h]$ (Ente Italiano di Normazione, 2008). $h_{i}>12 h$ is considered excellent for the Italian law (Italian Regulation, 1993);

The periodic thermal transmittance $Y_{m n}$ is complex quantity defined as the complex amplitude of the density of heat flow rate through the surface of the component adjacent to zone $m$ (external), divided by the complex amplitude of the temperature in zone $n$ (internal) when the temperature in zone $m$ is held constant (Ente Italiano di Normazione, 2008). Usually, in the building sector, only the steady-state transmittance is used for the calculation of wall and roof characteristics, but terms calculated from $Y_{m n}$ (such as $F_{a}$ and $\Phi$ ) play an important role in the building thermal behaviour (Rossi and Rocco, 2014).

Table 1 shows a global thermal value description of the 6 constructions. Specifically, for each material, the table shows thermal transmittance, decrement factor, time shift and surface mass (the mass of 1 squared meter of construction).

\section{Roof (code: $r X X$ )}

Similarly to external walls, 6 different roof constructions have been investigated. The choice of the construction followed the same criteria for external walls and a code (from r01 to r06) is assigned to constructions: i) $r 0120 \mathrm{~cm}$ thick concrete hollow slab, characterised by very high transmittance and very low time shift; ii) $r 0225 \mathrm{~cm}$ thick concrete hollow slab, characterised by high transmittance and low time shift. The case-study roof is built with this construction; iii) r03 $25 \mathrm{~cm}$ thick concrete hollow slab with 12 $\mathrm{cm}$ thick insulation layer. Transmittance and time shift meet Italian law requirements about retrofit intervention in heated rooms; iv) r04 $20 \mathrm{~cm}$ thick concrete hollow slab plus $12 \mathrm{~cm}$ thick insulating material: low transmittance and low time shift; v) r05 wooden slab: high transmittance and high time shift; vi) r06 high-performance construction, $13 \mathrm{~cm}$ of fibre-wood insulation is added solution r02: low transmittance and high time shift.

Appendix Table A2 lists the layers of the 6 constructions with

Table 1. Wall construction and thermal values.

\begin{tabular}{lcccc} 
& Th. transmittance $\mathbf{U}\left[\mathrm{Wm}^{-2} \mathrm{~K}^{-1}\right]$ & Decrement factor & Time shift $[\mathrm{h}]$ & 3.91 \\
w01 & 2.60 & 0.76 & 9.69 & 234 \\
w02 & 1.26 & 0.31 & 12.34 & 328 \\
\hline w03 & 0.29 & 0.14 & 5.19 & 141 \\
w04 & 0.31 & 0.59 & 10.72 & 140 \\
w05 & 2.42 & 0.17 & 22.77 & 906 \\
w06 & 0.19 & 0.02 & & 378 \\
\hline
\end{tabular}


their main thermal values (the material are listed starting from the external layer). Table 2 show a complete thermal value description of the 6 constructions.

The CLT technology (also known as X-LAM) is gaining increasing importance in the construction market also because of its seismic and thermal characteristics (Asdrubali et al., 2017). Even though it is mainly applied in residential buildings, it can significantly affect the thermal performance also in free running buildings. For this reason the constructions $w 03$ has been created using CLT thermal characteristics, and r05 is a solution typical for CLT buildings.

\section{Glazed surfaces (codes: gLP and gHP)}

For glazed openings two solutions are evaluated: i) $g L P$ (low performance): simple glazed windows $\left(U g=6 \mathrm{Wm}^{-2} \mathrm{~K}^{-1}\right)$ and air infiltration value equal to 0.5 changes per hour (case-study solution); ii) $g H P$ (high performance): double glazed windows $\left(U g=2.2 \mathrm{Wm}^{-2} \mathrm{~K}^{-1}\right)$ and air infiltration value equal to 0.3 changes per hour (according to UNI 13300 regulation and Italian laws for conditioned building in Emilia Romagna region.

\section{Orientation (code: $\mathrm{oXXX})$}

The main axis of the case-study building is $32^{\circ}$ North East oriented. As well known the building orientation can significantly affect the building thermal trends, therefore, besides the building actual orientation (code: o032) three building counterclockwise$90^{\circ}$-rotations have been simulated: $122^{\circ} \mathrm{N}, 212^{\circ} \mathrm{N}$ and $302^{\circ} \mathrm{N}$ (codes: o122, o212, o302).

\section{Shading surfaces (codes: sON and sOF)}

The solar radiation represents a critical factor for the building thermal behaviour. Actually the case-study building has no sun shading protection systems. This works aims to evaluate the contribution of a sun shading wall built close to the construction. The sun-shading wall is supposed built with a steel structure (Appendix Figure A1A) and the shade is created by Parthenocissus tricuspidata, a seasonal climbing plant (Appendix Figure A1B). The wall is 3 meters far from the building walls to allow working procedures, and is thought to protect two sides of the building (Figure 2) corresponding to the walls of the storage area, irrespectively of the orientation chosen for the simulation. The options for the simulations are two: i) $s O N$ sun-shading wall is simulated; ii) $s O F$ no sunshading wall is simulated.

The simulation takes into account the leaf coverage month by month according to Susorova et al. (2013).

\section{Years (code: y07 and y13)}

Obviously the thermal performance of any building, is determined by the outdoor environmental conditions such as temperature, humidity, rainfall, snowfall, etc. therefore the same building will experiment every year different thermal responses (if unconditioned) or energy needs (if provided by a temperature control). In particular one of the conditions that mostly affects the discomfort is the yearly average temperature. Preliminary studies, carried out on more than 600 sites distributed all over the world, showed a strong dependence of the yearly average temperature of the site on the total discomfort of the building (as defined in the Indicators for thermal performance assessment Section). Appendix Figure A2 shows one of the preliminary study results, including the fitting equation regression coefficient $-R^{2}=0.945$.

Since the study aims to assess the thermal performance of a building in a specific site, the weather data chosen for the simulations must: i) show an average temperature very similar to the typical average temperature of that site, $13.7^{\circ} \mathrm{C}$; ii) be collected as close as possible to the building; iii) include possible seasonal variations, in particular in the fermentation period (fall).

Several weather files are available on the Internet for energy simulations; nevertheless the closest weather station is located at the Bologna airport, $32 \mathrm{~km}$ north from the farm, in a different environment (urbanised site). To cope with this problem, the installation of a meteorological station in the farm, $100 \mathrm{~m}$ meters far from the winery building, allowed to create weather files based on the record of the main outdoor environmental characteristics in the last 10 years. Among those files, two in particular have been selected, 2007 (cod: $y 07)$ and 2013 (cod: $y 13)$, since: i) they both show the same average temperature $\left(14^{\circ} \mathrm{C} \pm 0.1{ }^{\circ} \mathrm{C}\right)$ similar to the yearly average temperature of the site; ii) they are based on the data collected by the farm weather station; iii) their trends during the fermentation period are different (August-December in 2013 was warmer than in 2007).

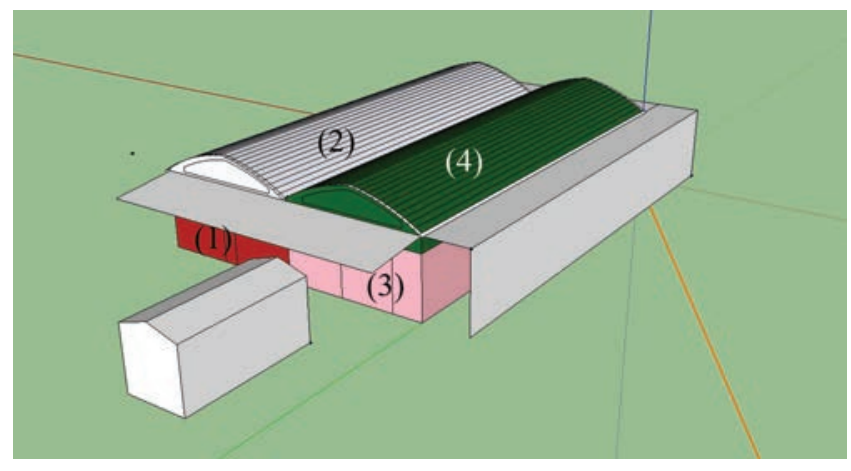

Figure 2. Thermal zones subdivision: 1) wine-making area; 2) wine-making roof area; 3) storage area; 4) storage roof area.

Table 2. Roof construction and thermal values.

\begin{tabular}{lcccc} 
& Th. transmittance $\mathbf{U}\left[W m^{-2} K^{-1}\right]$ & Decrement factor & Surface mass $\left[\mathrm{kg}^{-2}\right]$ \\
$\mathrm{r} 01$ & 2.01 & 0.73 & 4.70 & 302 \\
$\mathrm{r} 02$ & 1.66 & 0.50 & 6.83 & 293 \\
\hline $\mathrm{r} 03$ & 0.25 & 0.12 & 14.98 & 314 \\
$\mathrm{r} 04$ & 0.29 & 0.36 & 7.75 & 304 \\
$\mathrm{r} 05$ & 0.92 & 0.20 & 12.08 & 213 \\
$\mathrm{r} 06$ & 0.19 & 0.06 & 18.38 & 322 \\
\hline
\end{tabular}


Appendix Figure A3A shows the daily average temperature trends for 2007 and 2013, Appendix Figure A3B the monthly average temperature trends. The difference between the two years is also highlighted by the temperature distributions (Appendix Figure $\mathrm{A} 4 \mathrm{~A}$ and $\mathrm{B}$ ) and the solar horizontal radiation (Appendix Figure $\mathrm{A} 4 \mathrm{C}$ and D). The Kolmogorov Smirnov test rejects the null hypothesis $(P=0.677)$ that the two data sets have the same distribution; their dissimilarity index is equal to 0.125 .

\section{Energy modelling}

The rising interest on energy saving has driven the development and the diffusion of building energy modelling. Nowadays several programs are available to simulate energy needs and consumptions. For this work EnergyPlus 8.1 and OpenStudio 1.4 widely used by the scientific community (Mazarrón and Cañas Guerrero, 2008; Raftery et al., 2011; Benni et al., 2013; Heo et al., 2014; Barbaresi et al., 2015b) has been chosen for energy simulation and consequently for the prediction of building temperature trends.

The present research aims to provide an assessment of the all possible combinations of 6 wall constructions, 6 roof constructions, 4 building orientations, 2 windows solutions and 2 sun-shading situations from a thermal point of view. Totally 576 different building combinations are obtained, each building combination has run twice since two different years (2007 and 2013) are used as reference for outdoor environmental conditions. Thus 1152 simulations are run and their results analysed.

The EnergyPlus program works with garbage in garbage out standard entailing the precision in the input phase is crucial, thus a model of the case-study, calibrated and validated on experimental data, has been chosen [calibration and validation procedure are fully explained in Barbaresi et al. (2014) and Barbaresi et al. (2017)]. This model is considered the "base model and all the other models investigated in this work are obtained through variations of the architectural elements identified in the Design elements and variations Section.

The building is subdivided in 4 thermal zones [where a thermal zone is portion of the building volume in which the air temperature can be considered uniform (Barbaresi et al., 2015a)]: the wine making area, the wine-storage area and other two zones between the previous zones and the roof, as shown in Figure 2.

The shading surfaces have been modelled as EnergyPlus ShadingSurface Objects with solar transmittance equal to 1 . Then a specific Schedule Object has been created to control the transmittance according to the seasonal foliar coverage over the year. Specifically, the transmittance coefficient varies from 0.15 in summer to 0.90 in winter, taking into account both the foliar coverage and the steel structure.

The wine stored in the building represents a remarkable thermal mass affecting the building thermal behaviour (Benni et al., 2013). Wine and wine containers have been modelled as interior partition objects. The object size corresponds to the container size and the wine thermal characteristics have been taken from the scientific literature $\left[U=0.536 \mathrm{Wm}^{-2} \mathrm{~K}^{-1}\right.$, density $\delta=990 \mathrm{kgm}^{-3}$, specific heat $C=4500 \mathrm{Jkg}^{-1} \mathrm{~K}^{-1}$ (Boulton et al., 1998)].

The ground temperatures are based on the data collected during on-site ground temperature monitoring campaigns (Tinti et al., 2014, 2015). No internal loads are present in the building.

Scripts elaborated through Matlab software eased the creation of the architectural element variations combining them in the 1152 models. The model nomenclature is thought to ease the comprehension of the analysed combination. The model file name structure is $P 15 \_w X X r X X o X X X g X X s X X y X X$.osm where $P 15$ is the ref- erence of the research, $w X X, r X X, o X X X, g X X, s X X$ and $y X X$ represent the elements variations according to the codes explained in the Design elements and variations Section; for example the file P15_w02r02o032gLPSOFy13.osm - corresponding to the base model - is made by wall n. 2 , roof n. $2,32^{\circ} \mathrm{NE}$ oriented, low performance windows, no sun shading, year 2013. The 1152 files, generated as combinations of all variations, undergo to EnergyPlus simulations using RunManager (an OpenStudio application). The EnergyPlus program returns, among many results, the thermal zone yearly temperature trends hour by hour.

\section{Temperature analysis of building combinations}

The energy performance analysis for conditioned buildings is usually based on few indicators such as energy demand or energy consumption. These indicators drive directly to economical assessments such as operating cost, due to energy demand, and payback analysis, obtained by the comparisons between operating and construction costs. Since unconditioned, the building solutions investigated in this paper cannot be based on the same indicators.

Nevertheless their suitability to host wine can be assessed comparing the indoor environmental conditions with the ideal conditions for wine keeping and ageing. As above said, temperature and humidity play a basic role in wine keeping, but humidity affects the quality mainly when the wine is kept in wooden barrels because of mould and evaporation risks. In the case-study building the wine is kept and stored in stainless steel tanks and glass bottles, therefore the temperature is the only parameter used as reference for the building thermal behaviour assessment. Thus specific indicators (better explained in the Indicators for thermal performance assessment Section) based on the concept of thermal comfort, have been defined.

\section{Ideal temperature ranges and thermal comfort}

In this Section ideal temperature ranges for wine keeping and for human comfort will be discussed. These values will be used as reference to evaluate the suitability of each building combination to host wine or to host human activities. To uniform the terminology used in the present paper, the analysed intervals are called (human's or wine's) Temperature comfort ranges.

To define suitable temperature ranges for wine keeping and ageing, a comparative analysis - based on the scientific literature was carried out. Proposed values are significantly different depending on factors such as site, wine variety, quality, wine-making technology and many more. For example Troost (1953) recommends $9{ }^{\circ} \mathrm{C}-12^{\circ} \mathrm{C}$ for white wines, and $12^{\circ} \mathrm{C}-15^{\circ} \mathrm{C}$ for red wines, Marescalchi (1965) proposes temperatures between $15^{\circ} \mathrm{C}$ and $20^{\circ} \mathrm{C}$ in the first year and between $4^{\circ} \mathrm{C}$ and $12^{\circ} \mathrm{C}$ for the following years. Moreover the yearly temperature swings should be lower than $6^{\circ} \mathrm{C}$ (Vogt, 1971) overall in summer.

We can sum up that our scientific literature overview excludes the possibility to define a temperature range suitable for all the wine types and qualities, nevertheless studies confirm temperatures should be close to $15^{\circ} \mathrm{C}$, not higher than $20^{\circ} \mathrm{C}$ and excessive swing (larger than $+/-3^{\circ} \mathrm{C}$ ) must be avoided. For this work, according to the case-study production, two temperature intervals (thermal comfort ranges) have been defined: i) $\mathrm{TCl}: 15^{\circ} \mathrm{C} \pm 3^{\circ} \mathrm{C}$ suitable for the Sangiovese and Albana wines; ii) $T C 2$ : $10.5^{\circ} \mathrm{C} \pm 1.5^{\circ} \mathrm{C}$ suitable for the second fermentation in sparkling classic method.

Besides to suitability to host the wine, the present works aims to assess if the building combinations - appropriate for wine keeping - are suitable to host human activities as well.

Human thermal comfort is the condition of mind that expresses 
satisfaction with the thermal environment and is assessed by subjective evaluation (ANSI/ASHRAE, 2013). As explained by this definition, thermal comfort is related to the human wellness and substantially is subjective. Studies and regulations suggest the appropriate indoor temperatures depend on several factors such as metabolic rate, clothing insulations, climate region and outdoor conditions. In order to provide a simple tool able to assess the ideal comfort temperature, McCartney and Fergus Nicol (2002) developed the adaptive control algorithm using comfort field studies across Europe. Therefore the third temperature comfort range in this work $(T C 3)$ is defined as:

$$
\begin{array}{ll}
T_{C o}=0.302_{R M 80}+19.39^{\circ} \mathrm{C}, & \text { with } T_{R M 80}>10^{\circ} \mathrm{C} \\
T_{C o}=22.88^{\circ} \mathrm{C}, & \text { with } T_{R M 80}<10^{\circ} \mathrm{C}
\end{array}
$$

where with $T_{c o}$ is the temperature of comfort and $T_{R M 80}$ is the outdoor running mean temperature calculated with 0.80 coefficient. The acceptability range is defined by (El Mankibi, 2003) and is equal to $d T=-0.189 T_{c o}+6.35^{\circ} \mathrm{C}$.

\section{Indicators for thermal performance assessment}

The energy software returns, for each combination and for each thermal zone, the yearly indoor temperature trends ( $1 \mathrm{~h} \mathrm{step)}$. These values, compared to the Temperature comfort ranges will provide the suitability to host wine or human activities based on the following indicators.

\section{Discomfort level}

According to Barbaresi et al. (2017), the discomfort level [dh] assesses how much the indoor temperature gets out of the suitability range. The indicator, $D L$ is expressed in degree-hours and calculated as follows:

$D L=D L_{+}+D L_{-}$

with:

$$
\begin{gathered}
D L_{+}=\sum_{i=1}^{n} a\left(T_{i}-T_{\text {max }}\right) \text { where } a= \begin{cases}1, & T_{i}>T_{\max } \\
0, & T_{i} \leq T_{\max }\end{cases} \\
D L_{-}=\sum_{i=1}^{n} b\left(T_{\min }-T_{i}\right) \text { where } b= \begin{cases}0, & T_{i} \geq T_{\min } \\
1, & T_{i}<T_{\min }\end{cases}
\end{gathered}
$$

where $T_{\min }$ and $T_{\max }$ are the extremes of the chosen comfort range. The discomfort level $D L$ of the building is the sum of excessive discomfort level $D L_{+}$and defect discomfort level $D L_{-}$. The $D L_{+}$is the summation of all differences between the simulated temperature $T_{i}$ and the upper limit of the temperature comfort range $T_{\max }$, when the simulated temperature is over the upper limit. The $D L_{-}$is the summation of all differences between the lower limit of the temperature comfort range $T_{\min }$ and the simulated temperature $T_{i}$ when the simulated temperature is lower than the lower limit, $n$ is the number of hours in one year (8760). Since the building temperature trend depends on the outdoor weather condition, the discomfort level, for each combination, cannot be considered as an absolute value of that building but will be different every year.

\section{Discomfort reduction}

The discomfort reduction [\%] indicator is a comparison between indoor and outdoor temperature trends. It compares the discomfort levels of indoor and outdoor environments as follows:

$D R_{j}=\frac{D L_{0}-D L_{j}}{D L_{0}}$

$D R_{j}$ is the reduction of the discomfort of the building combination $j, D L_{j}$ is the discomfort level of the building combination $j$ and $D L_{0}$ is the Discomfort Level calculated on the outdoor temperature in the year of the simulation (2007 or 2013). In other words, the $D L$ indicator compares the thermal comfort of the investigated building with a hypothetical room - protected from wind and sun - in continuous thermal equilibrium with the outdoor environment.

\section{Rate of temperature change}

Another important condition for wine keeping is the thermal stability. The rate of temperature change $\left[{ }^{\circ} \mathrm{Ch}^{-1}\right]$ calculates the temperature hourly average change as follows:

$$
R o C=\frac{\sum_{i=2}^{n}\left|T_{i}-T_{i-1}\right|}{n-1}
$$

Lower values entail better temperature stability. This indicator is not influenced by the temperature comfort ranges.

\section{Results and discussion}

Appendix Figure A5 shows the yearly temperature averages for the investigated simulations. The building combinations are in the $x$ axis enumerated from 1 to 1152, the $y$ axis represents the yearly indoor average temperatures (expressed in ${ }^{\circ} \mathrm{C}$ ).

The graph highlights the wine-storage indoor temperature average is very similar to outdoor average, as expected, since no thermal source is present in the building (except the solar radiation). This result suggests the building can offer an indoor temperature condition suitable for temperature comfort ranges close to the outdoor average temperature, such as $T C 1$ and $T C 2$ and can hardly meet the TC3 needs. Appendix Figure A6 shows the distributions of the average (red circles) and standard deviation (blue boxes) of indoor temperatures calculated on the 576 models for 2007 (Appendix Figure A6A) and 2013 (Appendix Figure A6B). This graph shows basically two peaks of distribution around $7-8^{\circ} \mathrm{C}$ and $21-23^{\circ} \mathrm{C}$ centred on the yearly average temperatures $\left(14-15^{\circ} \mathrm{C}\right)$. These distributions clearly show that the calculated temperatures are often out of the selected TC ranges (for 4800-5200 h on 8760). Nevertheless they show that discomfort levels increase if TC is far from the yearly average temperature, as demonstrated in the following Sections. The trends are compatible with outdoor temperature distributions of 2007 and 2013 that are depicted by the orange lines (Appendix Figure A6) representing the Kernel density estimation, a non-parametric way to estimate the probability density function of a variable. The Kolmogorov Smirnov test rejects the null hypothesis $(P=0.997)$ that the two data sets have the same distribution, their dissimilarity index, calculated on those two data sets, is 0.133 .

Energy-saving Italian law (Italian Regulation, 1993) takes as reference two specific days for winter and summer for system sizing, sun shading design, etc. Those days are December 21 and July 21. For this reason the average (red circles) and standard deviation (blue boxes) of daily temperatures of July and December, calculat- 
ed on all models, are shown in Appendix Figure A7 for 2007 and 2013. Given their the importance for the wine-making, the trends of October 2007 and 2013 are shown as well. It is interesting to highlight the lower standard deviation during winter and autumn, this meaning that in those periods the models have more similar thermal behaviour. Appendix Figure A7E and F show how temperatures in October are mainly within $T C 1$ range.

\section{Discomfort level}

As mentioned above, EnergyPlus simulation returns, for each model and each thermal zone, the yearly temperature trend hour by hour. The wine-storage temperature trends have been analysed as explained in the Ideal temperature ranges and thermal comfort Section. Table 3 exhibits the best and worst DL performance for each TC. First of all it is interesting to notice that the best and the worst models for $\mathrm{TCl}$ accordingly induce the best and worst performance also for TC2. Moreover the best and worst performances are obtained by models composed by the same variants in terms of orientation, glazing, shading and year (i.e., o032; gHP; sON; y07), which means that the influence of those variables on the thermal behaviour cannot be compared to that of roof and walls, as we will demonstrate in more detail in this Section. As it could be expected, scarcely insulated roof and walls $(w 01, r 02)$ lead to the worst performance, and the best one is obtained by the elements with the highest values of insulation and time shift (w06, r06). Differently, the best model for TC3 consists of w05 (low insulation, high time shift) and $\mathrm{r01}$ (worst values of insulation and time shift).

In the Appendix Figure A8 the discomfort levels, for each model and each temperature comfort range, are shown. The building combinations are in the $x$ axis enumerated from 1 to 1152 , the TC3 axis represents the discomfort level (expressed in $d h \times 10^{4}$ ). Three colours have been used according to the 3 temperature comfort ranges. This graph shows first of all the results are confined in precise slots according to the comfort ranges (some overlap is visible between $T C 1$ and TC2), moreover the TC1 and TC2 results produce same trends, and the higher values of the $T C 2$ analysis is probably given by the smaller acceptability interval $( \pm 1.5 \mathrm{vs}$ $\pm 3^{\circ} \mathrm{C}$ ). The $T C 3$ results exhibit higher values, the reason can be that the human thermal comfort is often set over $23^{\circ} \mathrm{C}$, a temperature very far from the indoor average temperature $\left(14^{\circ} \mathrm{C}\right)$.

Reading the results in the graph horizontally, results appeared to be grouped in sort of clusters, each cluster of data shows evident discontinuities. These discontinuities appear when there is a change of architectural element (mainly wall and roof, but also the other variables): this reveals that architectural elements have different influence on the thermal performance of the building. For this reason, more in depth analyses have been made in order to rank the importance of each variable (walls, roof, etc.) and each variation $(w 01, w 02, \ldots, r 01$, etc.). Specifically, for each TC, we have isolated all the simulations containing a single element variation (for example w01), and calculated the quartiles of its discomfort level distribution (see box-plots in Figures 3-5). In order to rank the influence of each variable (i.e. walls), we have calculated the standard deviation of all the medians of the discomfort level (Table 4) for the selected variable $(w 01, \ldots, w 06)$ calculating also the median of all 1152 simulations (see tot label in Figures 3-5). The highest the standard deviation, the bigger the influence that the selected variable has on the total discomfort of the building

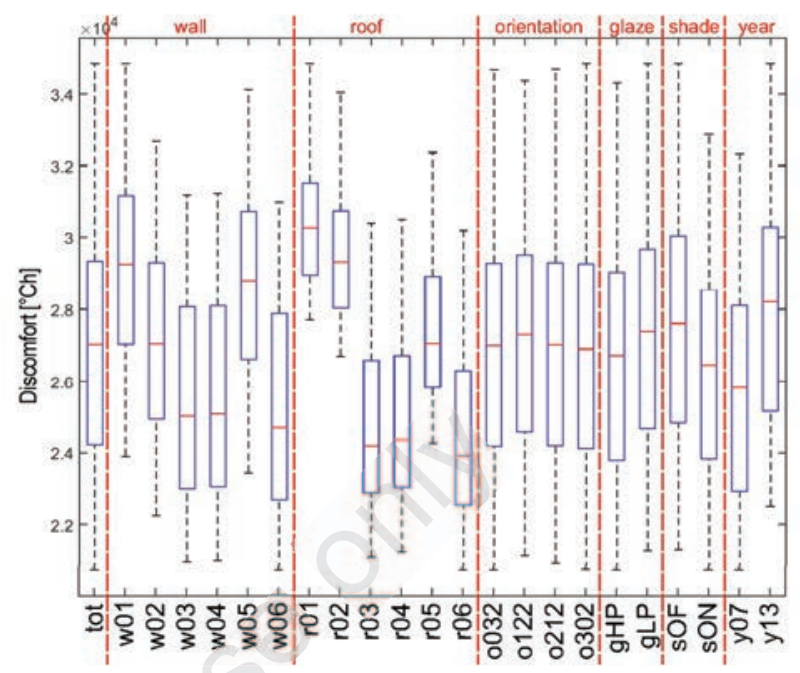

Figure 3. Boxplots for each architectural variation calculated on TC1. Y axis represents the discomfort level [dh] Inner and outer fences are depicted with dash line.

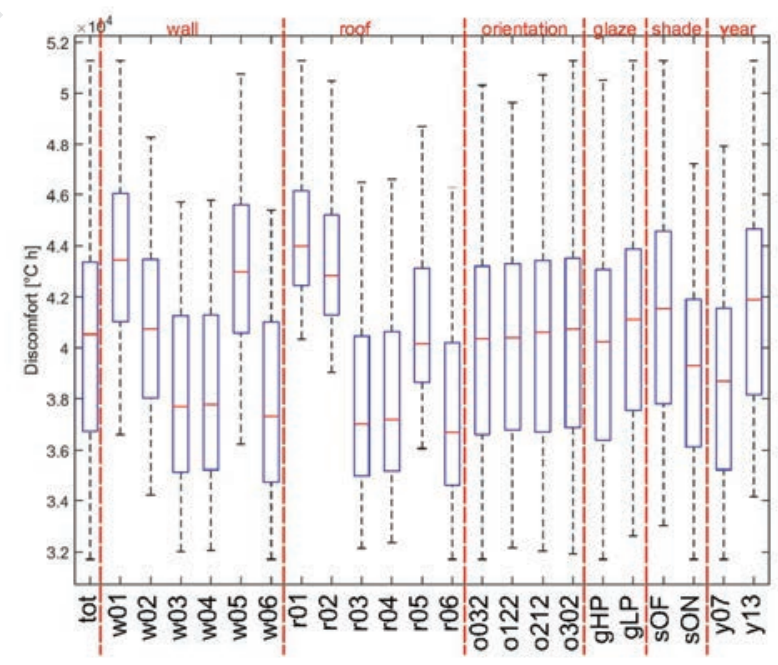

Figure 4. Boxplots for each architectural variation calculated on TC2. Y axis represents the discomfort level [dh] Inner and outer fences are depicted with dash line.

Table 3. Highest and lowest $D L$ values and related combinations in degree-hours.

\begin{tabular}{lll} 
& \multicolumn{1}{c}{ Max } & Min \\
TC1 & $34842\left(\mathrm{P} 15 \_w 01 r 020032\right.$ gHPsONy07) & 20734 (P15_w06r060032gHPsONy07) \\
TC2 & 51257 (P15_w01r020032gHPsONy07) & 31726 (P15_w06r060032gHPsONy07) \\
\hline TC3 & $80015($ P15_w06r060032gHPsONy13) & 66696 (P15_w05r010302gLPsOFy07) \\
\hline
\end{tabular}


(Table 4). Moreover, the interquartile range IQ $(I Q=Q 3-Q 1)$ of each variation has been used to rank its influence on the discomfort level of the model: the smaller the interquartile, the bigger the influence (Table 5). It is interesting to notice that the Table 5 shows the constructions ranked by their influence on the building thermal performance, but the rank does not give information if the construction affects positively or negatively the performance, for example, for TC1, r04 and r05 have similar rank but the first gives a positive contribution to the building thermal performance, the second affects negatively the building thermal behaviour.

Comparing alternatives belonging to the same design set, in $T C 1$ and TC2 (Figures 3 and 4), it is clear the orientation has small influence, since the orientation variations (o32-o212) show similar box-plot values, the high-performance windows $(g H P)$ and the sun-shading insertion $(s O N)$ slightly improve the building performance, the outdoor weather conditions affect significantly the performance (see tot, y07 and y13) and highest influence is achieved by wall and roof variations, in particular scarcely insulated constructions exhibit the worst performances. The analysis of the TC3 results confirms the limited influences of orientation, windows and sun shading and higher influence played by wall and roof constructions, but differently from $T C 1$ and $T C 2$, better performances are

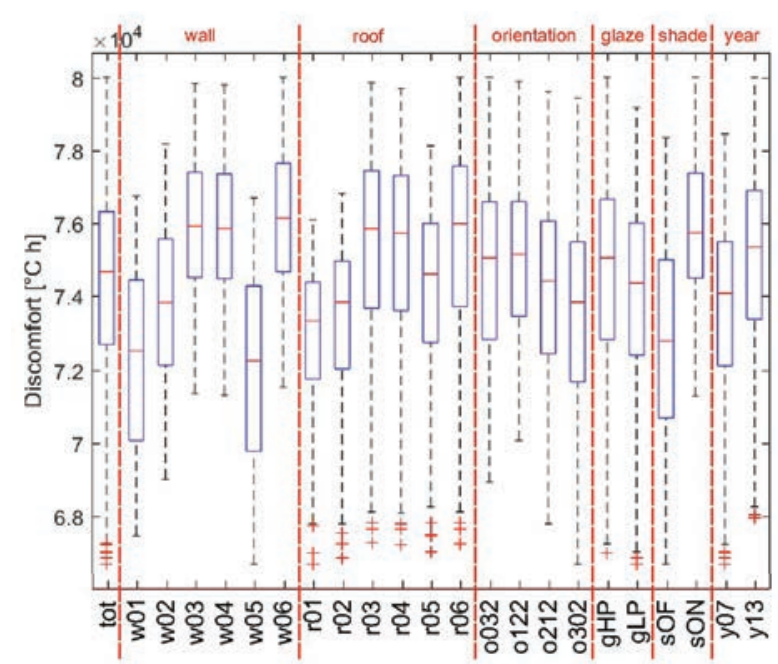

Figure 5. Boxplots for each architectural variation calculated on TC3. Y axis represents the discomfort level [dh]. Inner and outer fences are depicted with dash line. Red "+" symbols indicate the outliers falling outside the inner fence $Q 1-1.5 \mathrm{I} Q$.

Table 4. Variable influence on discomfort level.

\begin{tabular}{|c|c|c|c|c|c|c|}
\hline N. & & & & & & \\
\hline & Variable & St. dev. [dh] & Variable & St. dev. $[\mathrm{d} h]$ & Variable & St. dev. [dh] \\
\hline 1 & Roof & 2606.7 & Roof & 3047.5 & Roof & 1675.6 \\
\hline 2 & Walls & 1882.4 & Walls & 2590.5 & Shading & 1416.3 \\
\hline 3 & Year & 1202.0 & Year & 1607.8 & Walls & 1049.1 \\
\hline 4 & Shading & 577.0 & Shading & 1120.0 & Orientation & 603.0 \\
\hline 5 & Glazing & 333.0 & Glazing & 460.9 & Year & 333.4 \\
\hline 6 & Orientation & 150.6 & Orientation & 146.3 & Glazing & 311.7 \\
\hline
\end{tabular}

St. dev., standard deviation.

Table 5. Variation influence of the variations on discomfort level.

\begin{tabular}{|c|c|c|c|c|c|c|}
\hline \multirow{2}{*}{ N. } & \multicolumn{2}{|c|}{ TC1 } & \multicolumn{2}{|c|}{ TC2 } & \multicolumn{2}{|c|}{ TC3 } \\
\hline & Variation & IQ [dh] & Variation & IQ [dh] & Variation & IQ [dh] \\
\hline 1 & r01 & 2563 & r01 & 3707 & r01 & 2651 \\
\hline 2 & r02 & 2701 & r02 & 3901 & $\mathrm{sON}$ & 2864 \\
\hline 3 & r05 & 3102 & r05 & 4463 & $\mathrm{r} 01$ & 2865 \\
\hline 4 & r04 & 3686 & w01 & 5016 & w03 & 2881 \\
\hline 5 & r03 & 3708 & w05 & 5034 & r02 & 2949 \\
\hline 6 & $\mathrm{r} 06$ & 3762 & w02 & 5434 & w06 & 2962 \\
\hline 7 & w05 & 4114 & r04 & 5463 & 0122 & 3150 \\
\hline 8 & w01 & 4149 & $\mathrm{r} 03$ & 5510 & r05 & 3250 \\
\hline 9 & w02 & 4373 & r06 & 5620 & y07 & 3385 \\
\hline 10 & $\mathrm{sOF}$ & 4717 & sOF & 5782 & w02 & 3455 \\
\hline 11 & 0122 & 4932 & w04 & 6107 & yl3 & 3541 \\
\hline 12 & gHP & 4995 & w03 & 6153 & gHP & 3609 \\
\hline 13 & w04 & 5043 & w06 & 6300 & 0212 & 3617 \\
\hline 14 & w03 & 5076 & gHP & 6316 & $\mathrm{r} 04$ & 3718 \\
\hline 15 & yl3 & 5106 & y07 & 6337 & 0032 & 3754 \\
\hline 16 & 0212 & 5109 & 0122 & 6491 & $\mathrm{r} 03$ & 3790 \\
\hline 17 & 0032 & 5115 & yl3 & 6496 & 0302 & 3826 \\
\hline 18 & 0302 & 5154 & 0032 & 6591 & gLP & 3830 \\
\hline 19 & y07 & 5189 & 0302 & 6615 & r06 & 3875 \\
\hline 20 & w06 & 5195 & gLP & 6698 & $\mathrm{sOF}$ & 4329 \\
\hline 21 & $\mathrm{sON}$ & 5199 & 0212 & 6701 & w01 & 4390 \\
\hline 22 & gLP & 5255 & sON & 6754 & w05 & 4526 \\
\hline
\end{tabular}


achieved by $s O F$ and $g L P$ and by scarcely insulated constructions (Figure 5).

The explanation can be given by the fact that high-performance windows and insulation materials are designed to reduce energy needs in conditioned buildings decreasing the thermal exchange between outdoor and indoor space (whose temperature is usually controlled by thermal systems). Therefore these solutions, in free-running buildings, helps to keep steady the indoor temperature whose average, in one year, is very similar to outdoor average temperature. Since outdoor average temperature is about $14^{\circ} \mathrm{C}$, high-performance architectural variables help to keep indoor temperature within $T C 1$ and $T C 2$ ranges (close to $14^{\circ} \mathrm{C}$ ) and out of TC3 range.

This explains also the sun-shading effect: the sun exposure is an external thermal source and - rising the building envelope temperatures - has a negative effect on $T C 1$ and $T C 2$ and a positive effect on $T C 3$, overall in winter and middle seasons. Another interesting aspect can be noticed analysing the architectural element that provides the best average performance in TC3: the element w05 (Figure 5). w05 is a thick brick wall, with high transmittance and high time shift, typical wall construction of traditional Mediterranean buildings. These buildings, that are proven expensive to be conditioned (due the wall high transmittance values), are felt as a comfortable shelter by inhabitants during extreme seasons since their envelope helps to reach a human thermal comfort as confirmed by recent studies (Ascione et al., 2015).

As explained before, the wall and the roof variations exhibit the highest influence on the building thermal behaviour. To know the contribution of the 36 possible wall-roof combinations, the other architectural variations have been fixed to the original building configuration (orientation $32^{\circ} \mathrm{NE}$, simple glazing, no sunshading, year 2013) and the discomfort levels of the combinations are shown in Figure 6. The matrices in the figure show the thermal discomfort obtained by the combination of walls (rows) and roof (columns) ceteris paribus. Each element of the matrices reports the value of the discomfort level in that particular combination of walls and roof. Grey scale have been reported to give an immediate assessment of the combination: the darker the colour, the better the performance.

These matrices confirms the best solution is to use the high performance constructions $(r 06-w 06)$ to obtain indoor temperatures close to $T C 1$ and $T C 2$. Differently the best solutions for TC3 would be w01-r05 and w05-r05 entailing high transmittance for the walls and high time shift for the roof should be considered during the design phase.

\section{Discomfort reduction}

As described in the previous Discomfort reduction Section, the discomfort levels were applied to the outdoor temperatures of 2007 and 2013 in order to calculate the reference values $\left(D L_{0}\right)$ for the discomfort reduction. Results are summed in Table 6. Despite the same yearly average temperature, 2007 and 2013 (used as reference for discomfort reduction) provide different discomfort levels calculated on TC1, TC2 and TC3. The discomfort level calculated on 2013, compared to discomfort level calculated on 2007, is $9 \%$ higher for $T C 1,10 \%$ higher for TC2 and $2 \%$ lower for TC3.

These values are compared to respective discomfort levels calculated on each building combination according to the Equation 6, and the results of comparisons are shown in Appendix Figure A9. Similarly to discomfort levels (Appendix Figure A8), the discomfort reductions exhibit a dependence on variable changes.

This indicator confirms what seen analysing the discomfort level indicator. The performance difference between TC1 and TC2 results is still visible, even though reduced since the thermal comfort acceptability ranges $\left( \pm 3^{\circ} \mathrm{C}\right.$ and $\left.\pm 1.5^{\circ} \mathrm{C}\right)$ are applied also to calculate the reference values. The best performance of TCl can be explained again considering that the $T C 1$ values are closer to the year average temperature. Interesting to notice that some combinations show negative reductions for TC 3, meaning the indoor environment scores more discomfort than outdoor environment. This is due by the fact that some solutions are designed to maintain the indoor temperature and, during winter time, the indoor temperature can reach very low values even when the outdoor temperature starts to be warmer and therefore closer to the considered thermal comfort range.

\section{A) TC1}

\begin{tabular}{l|r|r|r|r|r|r|} 
& r01 & r02 & r03 & r04 & r05 & r06 \\
\hline w01 & & 49498 & 45479 & 45600 & 47691 & 45259 \\
\hline w02 & 47737 & 46765 & 41716 & 41866 & 44518 & 41431 \\
\hline w03 & 45399 & 44233 & 38046 & 38227 & 41519 & 37678 \\
w04 & 45461 & 44304 & 38133 & 38317 & 41590 & 37769 \\
\hline w05 & 9994 & 49140 & 45042 & 45159 & 47304 & 44818 \\
\hline w06 & 45087 & 43918 & 37561 & 37760 & 41151 & 37179 \\
\hline
\end{tabular}

B) TC2

\begin{tabular}{l|rrrrrrr|} 
& r01 & r02 & r03 & r04 & r05 & r06 \\
w01 & 71019 & 70868 & 71275 & 71247 & 70940 & 71283 \\
w02 & 71780 & 72110 & 73534 & 73458 & 72741 & 73578 \\
w03 & 73505 & 73987 & 76356 & 76213 & 74981 & 76468 \\
w04 & 73448 & 73947 & 76276 & 76147 & 74919 & 76390 \\
\hline w05 & 70180 & 70352 & 71090 & 71035 & 70687 & 71093 \\
w06 & 73636 & 74167 & 7666 & 76528 & 75215 &
\end{tabular}

\section{C) TC3}

\begin{tabular}{l|r|r|rrrrr|} 
& r01 & r02 & r03 & r04 & r05 & r06 \\
\hline w01 & 75214 & 75654 & 76212 & 76208 & 74974 & 76234 \\
w02 & 75517 & 76148 & 76811 & 76809 & 75386 & 76856 \\
\hline w03 & 76792 & 78029 & 79429 & 79396 & 76725 & 79563 \\
w04 & 76739 & 77939 & 79291 & 79262 & 76657 & 79423 \\
\hline w05 & 76046 & 76947 & 77906 & 77889 & 75968 & 77995 \\
\hline w06 & 76841 & 78105 & 7956 & 79526 & 76768 &
\end{tabular}

Figure 6. Matrices showing the discomfort levels varying the wallroof combination referred to a specific thermal comfort range, ceteris paribus.

Table 6. Reference values in degree-hours.

\begin{tabular}{lll} 
& 2007 & 2013 \\
TC1 & 42,183 & 45,871 \\
TC2 & 54,657 & 60,113 \\
\hline TC3 & 80,933 & 79,687 \\
\hline
\end{tabular}




\section{Rate of temperature change}

Since the thermal stability is an important condition to evaluate the building thermal behaviour, the rate of temperature change coefficients have been calculated as described in the previous Rate of temperature change Section. As previously explained, this indicators does not depend on the temperature comfort. As reference, the $R o C$ is calculated on the outdoor temperatures for the simulation periods, scoring $1025 \mathrm{dh}$ for 2007 and $1073 \mathrm{dh}$ for 2013.

Appendix Figure A10 shows the trends of temperature variations. Specifically, the blue line is the average outdoor temperature calculated on 2007 and 2013, while the orange line is the average indoor temperature variations calculated on the models. The graph shows immediately the remarkable reduction of hourly temperature variations provided by buildings: the outdoor variations often overtakes $2^{\circ} \mathrm{Ch}^{-1}$, reaching $6^{\circ} \mathrm{Ch}^{-1}$ peaks, the average indoor is always lower than $1^{\circ} \mathrm{Ch}^{-1}$, entailing the building plays positive role in the hourly temperature swing reduction. The following graph (Appendix Figure A11) indicates that all the combinations strongly reduce the $\operatorname{RoC}\left(0.099^{\circ} \mathrm{Ch}^{-1}\right.$ to $\left.0.377^{\circ} \mathrm{Ch}^{-1}\right)$, showing the building improve the protection of the indoor environment from temperature swings if compared to outdoor conditions. The least insulated (wall and roof) solutions prove to have a higher $\mathrm{RoC}$ indicator (Figure 7).

\section{Configuration assessment}

The indicator proposed in this work can be summarised in a table showing the performance of each building configuration. Table 7, for two configurations chosen as examples, shows: an example of two configurations exhibiting the name of model, the discomfort level in degree-hours related to the considered thermal comfort ranges, the discomfort reduction between the model and the reference year, and the hourly average variation. In this work we used 2013 and 2007 for research purposes (on-site measurements for the calibration and validation of the model), but in the design phase, once the model is calibrated, the simulation should be run using a standard weather file for energy simulations representing the typical year in the specific region, since this can return a more precise simulation for energy saving purposes. Data in Table 7 can lend support to design decisions, since it allows the designers and other experts involved in the design process to easily compare two or more solutions.

\section{Conclusions}

The research aimed to assess the influence of architectural variations on the building thermal behaviour, and thus to help the professionals involved in the design of new buildings or retrofit interventions to analyse the suitability of the building without temperature control systems, to host food (wine) or, as alternative, to host human activities. These evaluation are made assessing the thermal performance achieved varying the architectural elements.

Observing all the simulated models, the indoor average temperature is very similar to outdoor average temperature (as expected since the solar radiation is the only thermal source) entailing, as first result, indoor environment can be more suitable for temperature comfort ranges closer to the outdoor average temperature (i.e., wine temperature comfort range). The temperature distance between the average temperature and the human comfort temperatures, highlights the indoor temperature can hardly meet the human temperature needs in the Mediterranean area. All the investigated building combinations show a strong temperature swing reduction with respect to the outdoor environment.

More specifically, among the analysed architectural set variations, walls and roof proved to have the highest influences on the thermal behaviour, but their thermal properties (time shift and transmittance) can provide positive or negative effects on the comfort level according to the reference temperature comfort range. For example the most insulated materials have positive effects for temperature ranges close to the yearly average, $T C 1$ and $T C 2$, and negative for TC3. High values of time shift (therefore low level of decrement factors) seem to play a positive role.

The orientation does not play a crucial role in the thermal behaviour, nevertheless we consider this result strongly connected

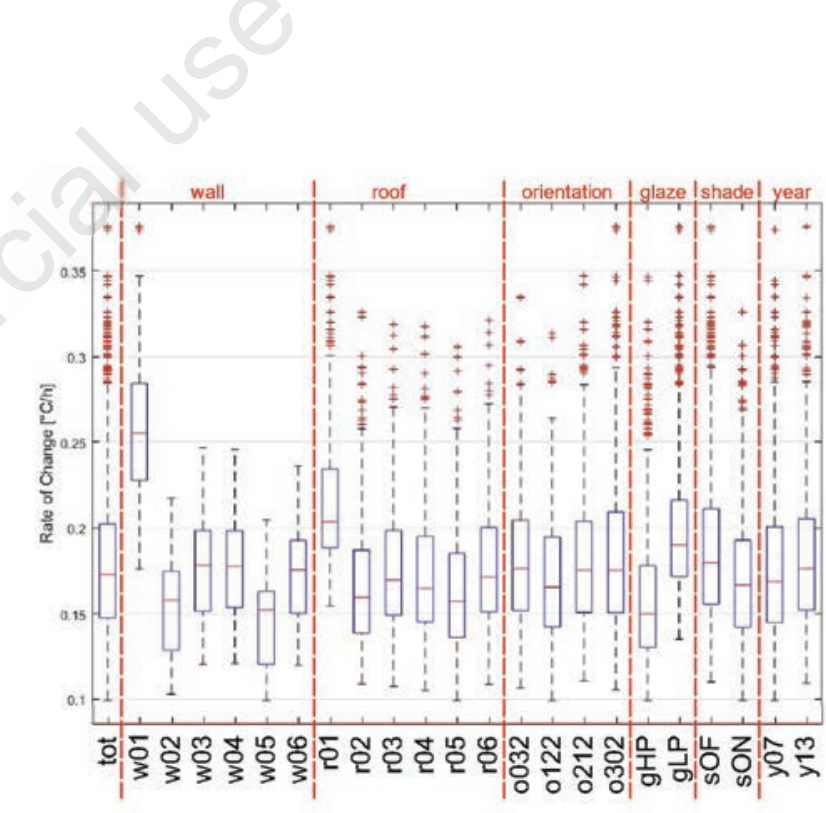

Figure 7. Boxplots related to Rate of temperature change for each architectural variation. Inner and outer fences are depicted with dash line. The outliers, calculated as value beyond the outer fence $Q 3+1.5 \mathrm{I} Q$, are indicated using the red "+"symbol.

Table 7. Final table (example).

\begin{tabular}{|c|c|c|c|}
\hline Configuration & Discomfort level [dh] & Discomfort reduction [\%] & $\operatorname{RoC}\left[{ }^{\circ} \mathrm{C}\right]$ \\
\hline P15_w02r02o032gLPSOFyl3 & $\begin{array}{l}31,881 \\
46,765 \\
76,148\end{array}$ & $\begin{array}{c}30.5 \\
22.2 \\
4.5\end{array}$ & 0.176 \\
\hline P15_w06r060032gLPsOFy13 & $\begin{array}{l}24,348 \\
37,179 \\
79,696\end{array}$ & $\begin{array}{c}46.9 \\
38.2 \\
0.0 \\
\end{array}$ & 0.215 \\
\hline
\end{tabular}


to the building shape (symmetrical, wide surface, small height). Likewise wall and roof variation, the contribution of sun-shading and high-performance windows can be positive or negative referred to the temperature comfort range required. A great influence on the comfort performance provided by the building, is given by the outdoor conditions: the simulations run in the 2 years (very similar in temperature average, but different in temperature trends) returned average differences of $10 \%$ in the discomfort level. Summing up the high-performance solutions designed to reduce energy consumption, do not necessarily give a positive contribution in unconditioned building; as matter of fact they are designed to reduce the heat transfer, meaning they tend to keep the indoor temperature. Thus, in free running buildings, they are useful only if the temperature range is close to the outdoor average temperature, as it occurs for TC1 and TC2, but not for TC3.

Finally the present work demonstrated that: i) the building solutions designed to reduce energy consumption in conditioned building can give a negative contribution to the indoor thermal comfort if the thermal comfort range is far to the yearly average temperature; ii) all the investigated solution show a significant temperature swing reduction; iii) the most common building envelope energy saving solutions do not avoid temperature discomfort periods, entailing a conditioning system is always needed when discomfort is unacceptable (for example human activities, high quality food product, food safety), but can be acceptable for nonhigh-quality wines; iv) similar thermal performances can be achieved combining very different architectural elements, entailing a design that considers these elements separately can be reductive; v) the proposed indicators have proven to be useful tools to assess the temperature suitability of a building to host a specific activity.

Future developments of this work will focus on different dimension and shape of the building, and will take into account conditioning systems

\section{References}

ANSI/ASHRAE. 2013. Thermal environmental conditions for human occupancy. Available from: https://www.ashrae.org /technical-resources/bookstore/thermal-environmental-conditions-for-human-occupancy

Ascione F., Bianco N., De Masi R., Mauro G., Vanoli G. 2015. Design of the building envelope: a novel multi-objective approach for the optimization of energy performance and thermal comfort. Sustainability 7:10809-36.

Asdrubali F., Ferracuti B., Lombardi L., Guattari C., Evangelisti L., Grazieschi G. 2017. A review of structural, thermo-physical, acoustical, and environmental properties of wooden materials for building applications. Build. Environ. 114:307-32.

Baglivo C., Congedo P.M., Fazio A., Laforgia D. 2014. Multiobjective optimization analysis for high efficiency external walls of zero energy buildings (ZEB) in the Mediterranean climate. Energy Build. 84:483-92.

Barbaresi A., Dallacasa F., Torreggiani D., Tassinari P. 2017. Retrofit interventions in non-conditioned rooms: calibration of an assessment method on a farm winery. J. Build. Perform. Simul. 10:91-104.

Barbaresi A., De Maria F., Torreggiani D., Benni S., Tassinari P. 2015a. Performance assessment of thermal simulation approaches of wine storage buildings based on experimental calibration. Energy Build. 307-16.

Barbaresi A., Torreggiani D., Benni S., Tassinari P. 2014.
Underground cellar thermal simulation: definition of a method for modelling performance assessment based on experimental calibration. Energy Build. 76:363-72.

Barbaresi A., Torreggiani D., Benni S., Tassinari P. 2015b. Indoor air temperature monitoring: a method lending support to management and design tested on a wine-aging room. Build. Environ. 86:203-10.

Benni S., Torreggiani D., Barbaresi A., Tassinari P. 2013. Thermal performance assessment for energy-efficient design of farm wineries. Trans. ASABE 56:1483-91.

Boulton Roger B., Singleton V.L., Bisson L.F., Kunkee R.E. 1998. Principles and practices of winemaking. Springer, New York, NY, USA.

Cooke G.M., Berg H.W. 1984. A re-examination of varietal table wine processing practices in california. clarification, stabilization, aging, and bottling. Am. J. Enol. Viticult. 35:137-42.

Ente Italiano di Normazione. 2008. UNI EN ISO 13786 thermal performance of building components. dynamic thermal characteristics. Calculation methods.

Heo Y., Graziano D.J., Guzowski L., Muehleisen R.T. 2014. Evaluation of calibration efficacy under different levels of uncertainty. J. Build. Perform. Simul. 8:135-44.

Italian Regulation. 1993. D.P.R. 26 Agosto 1993, N. 412 Regolamento recante norme per la progettazione, l'installazione, l'esercizio e la manutenzione degli impianti termici degli edifici ai fini del contenimento dei consumi di energia, in attuazione dell'art. 4, Comma 4.

Jiao Y., Hang Y., Zi W., Qi W., Yifan Y. 2017. Influence of individual factors on thermal satisfaction of the elderly in free running environments. Build. Environ. 116:218-27.

El Mankibi M. 2003. Développement et évaluation numérique et expérimentale de stratégies de régulation de la ventilation hybride. INSA Lion.

Marescalchi C. 1965. Manuale dell enologo (winemaking manual). Fratelli Marescalchi, Casale Monferrato, Italy.

Martin S., Canas I. 2006. A comparison between underground wine cellars and aboveground storage for the aging of Spanish wines. Trans. ASABE 49:1471-8.

Mazarrón F., Cañas Guerrero I. 2008. Exponential sinusoidal model for predicting temperature inside underground wine cellars from a Spanish region. Energy Build. 40:1931-40.

McCartney K.J., Fergus Nicol J. 2002. Developing an adaptive control algorithm for Europe. Energy Build. 34:623-35.

Raftery P., Keane M., O’Donnell J. 2011. Calibrating whole building energy models: an evidence-based methodology. Energy Build. 43:2356-64.

De Rosis A., Barbaresi A., Torreggiani D., Benni S., Tassinari P. 2014. Numerical simulations of the airflows in a wine-aging room: a lattice boltzmann-immersed boundary study. Comput. Electron. Agricult. 109:261-70.

Rossi M., Rocco V.M. 2014. External walls design: the role of periodic thermal transmittance and internal areal heat capacity. Energy Build. 68:732-40.

Susorova I., Angulo M., Bahrami P., Stephens B. 2013. A model of vegetated exterior facades for evaluation of wall thermal performance. Build. Environ. 67:1-13.

Tinti F., Barbaresi A., Benni S., Torreggiani D., Bruno R., Tassinari P. 2014. Experimental analysis of shallow underground temperature for the assessment of energy efficiency potential of underground wine cellars. Energy Build. 80:451-60.

Tinti F., Barbaresi A., Benni S., Torreggiani D., Bruno R., Tassinari P. 2015. Experimental analysis of thermal interaction between wine cellar and underground. Energy and Buildings 104:275-86. 
Torreggiani D., Benni S., Corzani V., Tassinari P., Galassi S. 2011. A meta-design approach to agroindustrial buildings: a case study for typical Italian wine productions. Land Use Policy 28:11-8

Troost G. 1953. Die Technologie Des Weines. Eugen Ulmer, Stuttgart, Germany.

Verdecchia A., Brunelli D., Tinti F., Barbaresi A., Tassinari P., Benini L. 2016. Low-cost micro-thermal response test system for characterizing very shallow geothermal energy. pp 1-6 in 2016 IEEE Workshop on Environmental, Energy, and Structural Monitoring Systems (EESMS), USA. Available from: http://ieeexplore.ieee.org/document/7504817/?reload= true\&arnumber $=7504817$

Vogt E. 1971. Fabricacion de vinos (winemaking). Editorial Acribia, Zaragoza, Spain. 